\title{
Underlying Mechanisms in the Relationship Between Africentric Worldview and Depressive Symptoms
}

\author{
Enrique W. Neblett Jr., \\ Department of Psychology, University of North Carolina at Chapel Hill \\ Eleanor K. Seaton, \\ Department of Psychology, University of North Carolina at Chapel Hill \\ Wizdom Powell Hammond, and \\ Department of Health Behavior and Health Education, University of North Carolina at Chapel Hill, \\ Gillings School of Global Public Health \\ Tiffany G. Townsend \\ Department of Psychiatry, Georgetown University School of Medicine
}

\begin{abstract}
This study examines underlying mechanisms in the relationship between an Africentric worldview and depressive symptoms. Participants were 112 African American young adults. An Africentric worldview buffered the association between perceived stress and depressive symptoms. The relationship between an Africentric worldview and depressive symptoms was mediated by perceived stress and emotion-focused coping. These findings highlight the protective function of an Africentric worldview in the context of African Americans' stress experiences and psychological health and offer promise for enhancing African American mental health service delivery and treatment interventions.
\end{abstract}

\section{Keywords}

Africentric worldview; stress; coping; resilience; depression

\begin{abstract}
Worldview — defined broadly as a structure of philosophical assumptions, values, and principles that guides one's perceptions and behaviors (Myers, Montgomery, Fine, \& Reese, 1996) - has been linked with indices of psychological adjustment such as emotional states and feelings of well-being (Frank, 1977). As interest in developing culturally relevant frameworks for understanding African Americans has increased over the last 2 decades, an Africentric worldview - a worldview of African origins - has been recognized as a cultural construct with implications for African Americans' stress experiences and health outcomes (e.g., Hatter \& Ottens, 1998; Myers et al., 1996). Building on the seminal work of African-centered psychologists who have highlighted the beneficial nature of an Africentric worldview in supporting healthy psychological functioning (e.g., Azibo, 1983; Baldwin \& Bell, 1985), contemporary scholars have proposed that an Africentric worldview acts as a protective factor against the harmful effects of stress (e.g., Belgrave, Townsend, Cherry, \& Cunningham, 1997; Jackson \& Sears, 1992).
\end{abstract}

(C) 2010 American Psychological Association

Correspondence concerning this article should be addressed to Enrique W. Neblett Jr., 250 Davie Hall, Department of Psychology, University of North Carolina at Chapel Hill, Chapel Hill, NC 27599-3270. eneblett@unc.edu. 
Despite the promise of an Africentric worldview as a culturally relevant construct for African Americans' mental health, few studies have examined the mechanisms by which it might convey its protective effects. In the present study, we examined the protective nature of an Africentric worldview in the association between perceived stress and psychological functioning in a sample of African American college students. In light of the oft-cited association between stress and depressive symptoms (e.g., Israelski et al., 2007; Shaver \& Brennan, 1991), and the heightened risk for depressive symptoms and depression during students' transition to college (Kashani \& Priesmeyer, 1983), we focused the investigation on depressive symptoms in first-year college students. A second focus of the study was to examine whether the relationship between an Africentric worldview and depressive symptoms was mediated by stress appraisals and/or coping strategies. The metagoal of these research objectives was to elucidate two mechanisms by which an Africentric worldview might operate to positively influence the mental health of African American young adults.

\section{An Africentric Worldview}

According to Myers (1988), worldviews vary across cultural groups and determine how individuals perceive, view, think, feel, and experience the world. An Africentric worldview is "the worldview of people of African descent" and consists of the values, beliefs, and behavior of people of African heritage (Belgrave \& Allison, 2006, p. 28). These values, beliefs, and behaviors-which are characterized by African interests, values, and perspectives-operate as a blueprint or template for people of African descent to live by, as a means for them to make sense of the world (Butler, 1992) and to adapt to life's circumstances (Nobles, 1980). Belgrave and Allison (2006) identified the following dimensions of an Africentric worldview: spirituality (belief in a being or force greater than oneself); collectivism (emphasis on cooperation); time orientation (equal importance attributed to past, present, and future and time flexibility); orality (preference for receiving stimuli and information orally); sensitivity to affect and emotional cues (acknowledgment of others' emotional and affective states); verve and rhythm (rhythmic and creative behavior); and balance and harmony with nature (balance between one's mental, physical, and spiritual states). These dimensions are thought to have sustained enslaved Africans who held onto them as a means of survival in an oppressive environment (Nobles, 1991) and to have been passed down through the generations (Asante, 2003; Grills, 2004; see Belgrave \& Allison, 2006, for a more detailed review).

Although scholars have talked about an Africentric worldview in a number of ways, optimal theory (Myers, 1988) describes it as an alternative, universal worldview that is "centered in Africa as the historical point of generation" (Myers et al., 1996, p. 19). An Africentric worldview can be described as optimal "if one places value on peace, harmony, balance and positive interpersonal relationships" (Myers et al., 1996, p. 20). Although there is disagreement among scholars with regard to whether an Africentric worldview is innately determined (e.g., see Kambon, 1992, 2004, for a biogenetic perspective), as well as whether it is exclusive to persons of African descent (see Azibo, 1996; Grills, 2004; Kambon, 2004, for an alternate perspective), most agree that it can be found to some extent among most people of African descent (Belgrave \& Allison, 2006).

Optimal theory (Myers, 1988) holds that an Africentric worldview is characterized by a nonmaterial, spiritual reality that places an emphasis on character traits such as honesty, integrity, trust-worthiness, and compassion, as opposed to more material, external criteria such as personal appearance, academic degrees, possessions, and renown. Africentric worldview also emphasizes material and spiritual unity. Mbiti (1970) further explained that individuals cannot exist alone; instead they exist harmoniously in relations to their ancestors, the unborn, nature, each other, the community, and everything else in the universe. Consistent with these assumptions, Africentric worldview values unity, cooperative effort, mutual responsibility, 
empathy, and reconciliation (Baldwin, 1981; Nobles, 1974). A final tenet of optimal theory concerns epistemology. Gaining knowledge results from a process of active engagement, or confronting challenges, which are often viewed as opportunities for growth.

\section{An Africentric Worldview and Psychological Adjustment}

Africentric worldview scholars have contended that an Africentric worldview plays an important role in African Americans' psychological adjustment (e.g., Baldwin \& Bell, 1985; Jackson \& Sears, 1992) and have even suggested that any deviation from an Africentric worldview or orientation could be equated with disorder or psychological dysfunction (Akbar, 1991; Azibo, 1996; Kambon, 1992, 2003). In an unpublished doctoral dissertation, Millet (1993) reported a link between worldview and Black university students' depression, such that lower Africentric worldview scores were associated with greater depression. In one of the few published studies to formally examine and operationalize an Africentric worldview, Hatter and Ottens (1998) found that an Africentric worldview was positively correlated with academic and personal-emotional adjustment in a sample of 67 African American college students attending a predominantly white institution (PWI). Although we are unaware of any recent studies to replicate these findings, both are suggestive of a link between an Africentric worldview and positive psychological adjustment.

One possible mechanism by which an Africentric worldview may positively influence psychological adjustment is through a buffering or moderating effect. Beliefs associated with an Africentric worldview may "act as a buffer between stressful life events and resultant poor health" (Myers et al., 1996, p. 22) by reducing the impact of stress. A particularly useful lens for understanding the potential protective nature of an Africentric worldview is Lazarus and Folkman's (1984) stress, appraisal, and coping theory. This paradigm focuses on stress (a relationship between the person and environment that is appraised as exceeding available resources), appraisal (one's perception and assessment of the situation), and coping (effortful or purposeful thoughts and actions to manage or overcome stressful situations; Frydenberg, 1997; Lazarus \& Folkman, 1984). Lazarus and Folkman (1984) characterized coping as problem-focused - referring to attempts to engage, act on, or change the actual stressor-and emotion-focused, referring to attempts to manage emotions associated with stressors. This overarching conceptual framework has often served as a useful framework for understanding African Americans' stress experiences (e.g., Harrell, 2000; Plummer \& Slane, 1996).

Lazarus and Folkman (1984) suggested five possibilities for the differential impact of stress on adjustment outcomes. First, they suggested that the misconstrual of stress as harmful or threatening when it is not, or the failure to appropriately recognize harm or threat, can exacerbate the impact of stress. Lazarus and Folkman noted that as a whole, individuals who tend to perceive stress as threatening instead of challenging (i.e., having the potential for gain or growth) are more likely to experience "withdrawal or defensive operations that turn the person inward" (p. 191). Second, a mismatch between the appraisal of available coping resources and the coping resources that are actually available can also result in negative outcomes. Third, people with more relaxed expectations regarding their own performance are less likely to be impacted by stress than are individuals with unrealistically high performance expectations, because high expectations may result in negative self-appraisal and feelings. Fourth, stress impacts psychological outcomes negatively when negative outcomes are seen as a product of a person's efforts instead of as a result of external factors. Fifth, Lazarus and Folkman suggested that coping effectiveness plays an important role in the impact of stress on adjustment outcomes. Effective coping results in "[handling] situations in a way such as to prevent stress or mitigate it when it occurs" (p. 198). We might expect that, on the basis of Lazarus and Folkman's theoretical model, an Africentric worldview would buffer the impact of stress by improving the accuracy and nature of stress appraisals, influencing individuals' 
accurate appraisals of available coping resources, altering performance expectations and negative attributions, and employing specific coping efforts that mitigate stress. Although these mechanisms seem plausible, we are unaware of any studies that evaluate either the moderating effect of or the underlying mechanisms of an Africentric worldview.

\section{The Present Study}

In the present study, we examine two potential mechanisms by which an Africentric worldview may lead to positive psychological adjustment. First, we examine whether an Africentric worldview moderates the impact of stress on depressive symptoms. We expect to find that, consistent with prior theory and conceptual work, an Africentric worldview will buffer the positive association between stress and depressive symptoms. A second aim is to examine perceived stress and coping as mediating influences in the relationship between an Africentric worldview and depressive symptoms. We expect that, with regard to stress, an Africentric worldview will be associated with decreased perceived stress and that stress will, in turn, act as a partial mediating factor in the relationship between an Africentric worldview and depressive symptoms. We expect that, with regard to coping, emotion- and problem-focused coping will mediate the relationship between an Africentric worldview and depressive symptoms. We expect that an Africentric worldview, which is thought to be linked with engaging challenges (Myers et al., 1996), will be positively related to problem-focused coping, which, in turn, will be negatively associated with depressive symptoms. Conversely, we expect that an Africentric worldview will be negatively related to emotion-focused coping, which, in turn, will be positively associated with depressive symptoms (e.g., Sasaki \& Yamasaki, 2007).

\section{Method}

\section{Participants}

The study sample included 112 (36 men and 76 women) 1st-year college students of African descent with no prior college experience who attended a large, state PWI in a rural setting in the northeastern United States. Study participants ranged in age from 18 to 20 years $(M=18.34$, $S D=0.49)$. Students self-identified their race/ethnicity as African American $(45 \%)$, West Indian/Caribbean Black (15\%), Black (12\%), African (12\%), Mixed (13\%), and Other (3\%). The majority of participants identified their family's socioeconomic status (SES) as middle $(52 \%)$ or working $(26 \%)$ class, and the remainder as upper middle class $(15 \%)$, lower class $(6 \%)$, or wealthy ( $1 \%)$. Concerning parents' education level, as reported by participants, a small minority of parents/guardians (6\%) had less than a high school diploma; approximately $22 \%$ of the sample had received a high school diploma; roughly $45 \%$ attended some college, business, or trade school or received a college diploma; and $26 \%$ completed some graduate or professional study or attained a graduate or professional degree (data were missing for $1 \%$ ). Lastly, most participants reported their physical and mental health status as good or very good ( $83 \%$ and $86 \%$, respectively).

\section{Variables}

Personal background-We assessed personal background variables with Section 1 of the Cross Racial Identity Scale (Worrell, Vandiver, \& Cross, 2000). This section consists of 23 items that ask individuals to report their gender, age, religious affiliation, primary community (i.e., the community in which the participant was raised), citizenship status, primary community's racial composition, parents' highest level of education, family's SES, and current physical and mental health status. In our analyses, racial composition of primary community, highest education level obtained by mother (or female guardian), highest education level obtained by father (or male guardian), and family's SES were evaluated as study covariates. 
Parental education level was scored on a 9-point scale ranging from 1 (Elementary school) to 9 (Graduate or professional degree). Finally, family SES was scored on a 5-point scale ranging from 1 (Poor) to 5 (Wealthy).

Africentric worldview-The Belief Systems Analysis Scale (BSAS; Montgomery, Fine, \& James-Myers, 1990) was used to measure participants' endorsement of Africentric beliefs or commitment to an Africentric (optimal) worldview, which is characterized by a "holistic, nonmaterialistic, and communal orientation" (Hatter \& Ottens, 1998, p. 474). The measure consists of 31 items reflecting hypothetical behaviors or situations characterized as either Africentric/optimal (e.g., "It is easy for me to see how the entire human race is really part of my extended family" and "Working a job with meaning and purpose is more important than the money received from a job") or non-Africentric/suboptimal (e.g., "English should be the only national language. If one wants to live in this country, one should learn to speak the language" and "If I had more money, my life would be more satisfying"). Items from the BSAS are rated on a 5-point Likert-type scale ranging from 1 (strongly disagree) to 5 (strongly agree) and are summed to create a composite score after reverse-coding the non-Africentric/ suboptimal items. Lower scores on this scale reflect a lesser adherence to the optimal Africentric belief system, whereas higher scores reflect a greater adherence to this belief system. The construct validity of the BSAS was initially evaluated in a sample of introductory psychology students and was supported by a positive correlation with social interests traits $(r$ $=.50)$ and a negative correlation with dogmatism $(r=-.51$; Myers et al., 1996). The internal consistency reliability (e.g., Cronbach's $\alpha$ coefficient) for this initial sample was .80 , and the 1-week test-retest reliability was .63. Brookins (1994) also validated the BSAS on 171 African American college students at a PWI and reported a Cronbach's alpha of .71. Brookins and Montgomery et al. (1990) have both reported evidence of good construct validity. For example, Brookins observed that the Africentric/optimal items of the BSAS correlated negatively $(r=$ $-.38)$ with the preencounter and positively $(r=.17)$ with the internalization subscales of the Racial Identity Attitudes Scale (Helms \& Parham, 1990). Montgomery et al., on the other hand, found scores on the BSAS negatively correlated with the Symptom Checklist-90-Revised (Derogatis, 1983), which assesses psychological distress. The Cronbach's alpha coefficient for the present sample is .71, suggesting acceptable internal consistency.

Perceived stress-We used a modified version of the Black Student Stress Inventory (BSSI; Edmunds, 1984) to assess the type and level of stress perceived by the participants. The BSSI is an 83-item measure designed to assess stressors commonly experienced by college students as well as potential stressors unique to African American students. This measure was originally developed from responses obtained during semistructured interviews conducted with African American students attending a PWI. Participants were asked to rate the 83 potential stressors with a 5-point Likert-type scale ranging from 1 (Not at all stressful for me) to 5 (Extremely stressful for me), and items were summed appropriately to yield two subscale scores: BSSIGeneral (BSSI-G; for general perceived stress) and BSSI-Culture-specific (BSSI-C; for culture-specific stress). In the present study, we used only the BSSI-G subscale. The BSSI-G subscale (60 items) reflects overall level of stress on the basis of responses to stress experienced by most college students (e.g., "selection of an academic major" and "roommate conflicts"). Internal consistency for the BSSI-G was high $(\alpha=.94)$. Neville, Heppner, and Wang (1997) reported evidence of good construct validity for the BSSI with the well-validated Daily Hassles Questionnaire (DeLongis, Coyne, Dakof, Folkman, \& Lazarus, 1982) in a sample of undergraduate African American students.

Coping styles-Coping approaches were measured with the Jalowiec Coping Scale (JCS; Jalowiec \& Powers, 1981). The JCS is a 40-item measure that asks individuals to describe the coping strategies they have employed to address the most stressful problems they have 
experienced in the last 6 months on a 5-point Likert-type scale ranging from 1 (never) to 5 (almost always). Previous factor analysis of this scale identified two major factors, one hypothesized to reflect problem-oriented (i.e., problem-focused) coping (15 items) and the other hypothesized to reflect affective-oriented (i.e., emotion-focused) coping (25 items; see Jalowiec, Murphy, \& Powers, 1984; Stein \& Nyamathi, 1999). Given our interest in how an Africentric worldview maps onto coping - and in order to improve the content validity for our hypotheses and for our use of the problem-focused/emotion-focused framework in the current study - we used a modified version of the original scale in the final analyses. Specifically, we eliminated one problem-focused coping item that we felt was inconsistent with an Africentric worldview (i.e., "Settled for next best thing to what you really wanted") and five emotionfocused subscale items that we felt were consistent with Africentric worldview (i.e., items on optimism, humor, praying/trusting God, getting comfort/help from others, and not worrying). Factor analysis supported grouping the 34 remaining items into two subscales that were consistent with the original two-factor solution. The revised subscales yielded two scores for each participant: a JCS-Problem-Focused Coping (JCS-PRB) score (14 items) and a JCSEmotion-Focused Coping (JCS-EMO) score (20 items). Items from these subscales were summed, and a mean score was computed such that higher scores reflected more employment of these strategies. The JCS has been used extensively in medically oriented research (e.g., Gulick, 1995). For example, Samuel-Hodge, Watkins, Rowell, and Hooten (2008) had a sample of African Americans with Type-2 diabetes complete the JCS and obtained Cronbach's alphas of .80, .74, and .69 on the Emotion-Focused Coping, Passive-Focused Coping, and ProblemFocused Coping subscales, respectively. Samuel-Hodge et al. also found negative correlations between the Problem-Focused Coping subscale and diabetes-related mental well-being $(r=-$. 16) and between the Emotion-Focused Coping subscale and general mental well-being $(r=-$. 52). Picot (1995) examined the coping styles of African American caregivers and obtained an alpha of .75 and .74 on the problem-focused and emotion-focused dimensions, respectively. In the present study, the Cronbach's alpha coefficients for the revised Problem-Focused Coping and Emotion-Focused Coping subscales were .81 and .78, respectively.

Depressive symptoms-We used the Beck Depression Inventory (BDI; Beck, Ward, Mendelson, Mock, \& Erbaugh, 1961) to assess depressive symptoms. The BDI is a 22-item forced-choice questionnaire (four choices per item) that is designed to assess the respondent's level of depressive symptoms. Level of depressive symptoms was computed by summing scores from all 22 items to yield a total sum score ranging from 0 to 66 . Scores of 10-18 suggest mild to moderate levels of depression, and scores above 18 suggest moderate to severe levels of depression. The BDI is considered to have excellent psychometric properties, with a splithalf reliability of .90 and a test-retest reliability of .75 (original sample). The validity of the BDI is sound as well, because BDI scores have consistently been found to correlate significantly with clinicians' ratings of severity of depression. More recently, Chapman, Kertz, and Woodruff-Borden (2009) had a sample of college students complete the BDI and obtained an alpha of .86 for the African American sample. Joe, Woolley, Brown, GhahramanlouHolloway, and Beck (2008) investigated the psychometric properties of the BDI-II among African American suicide attempters and reported an alpha of .94 along with good convergent validity supported by a positive correlation $(r=.66)$ with the Hamilton (1960) Rating Scale for Depression. In our sample, the overall alpha coefficient was .85 .

\section{Procedure}

Data collection occurred over the latter half of the spring semester. A list of self-identified first-year African American students was generated by the Multicultural Resource Center at the university to assist with the data collection process. Students on this list received several campus mailings/recruitment flyers briefly describing the study and providing contact information for setting up appointments. During data collection sessions, each participant 
received and signed a copy of the informed consent document and completed a paper-andpencil questionnaire that consisted of measures assessing the study variables. Upon completion of the questionnaires, students received a debriefing form and were provided with $\$ 10$ cash, refreshments, and ice cream gift certificates for their participation in the study.

\section{Results}

\section{Preliminary Analyses}

Preliminary analyses included a review of descriptive statistics and bivariate correlations for Africentric worldview, perceived stress, problem-focused coping, emotion-focused coping, and depressive symptoms (see Table 1). The mean for Africentric worldview was 105.69 $(S D=10.32)$, suggesting that the majority of participants fell within the Mixed Mainstream and Moderately Africentric category ranges (Myers et al., 1996). On average, the majority of participants rated perceived stress $(M=1.87, S D=0.65)$ as a little stressful to somewhat stressful. Participants endorsed problem-focused coping strategies about half the time $(M=$ $3.00, S D=0.59)$ and emotion-focused coping strategies occasionally $(M=2.03, S D=0.42)$. Finally, the mean count for depressive symptoms was $7.63(S D=6.26)$, suggesting low to mild levels of depressive symptoms in the current sample.

Several significant bivariate correlations were found among the study variables. Africentric worldview was negatively linked to general stress, emotion-focused coping, and depressive symptoms. Perceived stress was positively linked to emotion-focused coping and depressive symptoms. Finally, emotion-focused coping was positively linked to depressive symptoms.

\section{The Moderating Effect of Africentric Worldview}

The first aim of the study was to examine whether Africentric worldview moderated the relationship between perceived stress and depressive symptoms. To do so, we conducted a hierarchical multiple regression analysis (see Table 2 for a summary). Gender and family SES were included as covariates because they were found to be related to depressive symptoms in the bivariate analyses. We assessed all study variables for normality and found all values of skewness and kurtosis to be within acceptable ranges. Moderator analyses were conducted in a manner consistent with recommendations from Baron and Kenny (1986) and Holmbeck (1997). We centered the continuous predictor and moderator variables, as recommended by Cohen and Cohen (1983), to reduce multicollinearity between the main effect and interaction terms.

Stress was positively linked to depressive symptoms $(\beta=.55, p<.01)$, whereas Africentric worldview was negatively linked to depressive symptoms $(\beta=-.20, p<.05)$. There was a significant interaction between perceived stress and Africentric worldview (see Figure 1) in predicting depressive symptoms $\left(\beta=-.16, p<.05, \Delta R^{2}=.024\right.$ ) after we controlled for demographic variables. The slope of the line one standard deviation below the mean $(\beta=.11)$, $t(100)=11.40, p<.001$, and the slope one standard deviation above the mean $(\beta=.07), t(100)$ $=5.12, p<.001$, were significant. Stress scores positively predicted depressive symptoms at both levels of Africentric worldview; however, the strength of the association was greater at lower levels of Africentric worldview. This finding is consistent with Africentric worldview acting as a buffer of the association between perceived stress and depressive symptoms.

\section{Stress and Coping as Mediating Influences}

Our second aim was to assess the mediating roles of perceived stress and coping in the relationship between Africentric worldview and depressive symptoms. Specifically, we conducted mediator analyses to independently assess whether perceived stress, problemfocused coping, and emotion-focused coping mediated the relationship between Africentric 
worldview and depressive symptoms. Consistent with recommendations from Baron and Kenny (1986), MacKinnon and Dwyer (1993), and Holmbeck (1997), several conditions are required in order to demonstrate mediation. First, Africentric worldview should be related to the mediator variables as well as the indicator variable: depressive symptoms. Second, the mediating variables (stress and coping), must be significantly related to depressive symptoms. Finally, the strength of the association between Africentric worldview and depressive symptoms should decrease with the mediator variable also included in the model.

Problem-focused coping was not evaluated as a mediator because it was unrelated to Africentric worldview in the initial step of the mediation analyses. However, there was evidence for the mediating roles of perceived stress and emotion-focused coping in the relationship between Africentric worldview and depressive symptoms. With regard to perceived stress, the parameter estimates demonstrate that Africentric worldview was negatively linked to perceived stress $(\beta=-.32, p<.01)$ and depressive symptoms $(\beta=-.37, p<.001)$. Thus, higher endorsement of an Africentric worldview was associated with decreased levels of general stress and depressive symptoms. Perceived stress was also a significant predictor of depressive symptoms $(\beta=.51, p<.001)$. Finally, the association between Africentric worldview and depressive symptoms decreased but was still significant $(\beta=-.21, p<.05)$ with perceived stress in the full model. A partial mediation effect for perceived stress was supported by the Sobel test (see Preacher \& Leonardelli, 2001; $z=-3.04, p<.01$ ), suggesting that the relationship between Africentric worldview and depressive symptoms is accounted for, in part, by perceived stress (see Figure 2).

With regard to emotion-focused coping, we found that Africentric worldview was negatively related to emotion-focused coping $(\beta=-.34, p<.001)$ and depressive symptoms $(\beta=-.37, p$ $<.001)$. Thus, individuals who endorsed an Africentric worldview were less likely to employ emotion-focused coping strategies and experience depressive symptoms. Second, emotionfocused coping was significantly and positively associated with depressive symptoms ( $\beta=.46$, $p<.001$ ). Third, as with perceived stress, the association between Africentric worldview and depressive symptoms decreased but remained significant $(\beta=-.22, p<.05)$ when emotionfocused coping was included in the full model. Results of the Sobel test $(z=-5.24, p<.001)$ suggest that emotion-focused coping partially mediates the relationship between Africentric worldview and depressive symptoms (see Figure 3).

\section{Discussion}

Our first objective was to examine Africentric worldview as a protective factor against the impact of stress on depressive symptoms. A second aim was to explore the mediating influences of perceived stress and coping in the relationship between Africentric worldview and depressive symptoms. We provided evidence that individuals who endorse an Africentric worldview to a lesser extent are more likely to experience depressive symptoms at high stress levels when compared with those who endorse an Africentric worldview at higher levels. Our results also suggest that the relationship between Africentric worldview and depressive symptoms is accounted for, in part, by decreased perceptions of stress and emotion-oriented coping responses.

\section{Underlying Mechanisms}

How does an Africentric worldview protect against the impact of stress? One set of possibilities centers on the appraisal of stress. As we have noted previously, Lazarus and Folkman (1984) suggested that, in general, individuals who perceive stress as harmful or threatening are more likely to be negatively impacted by stress than are those who view stress as an opportunity for gain or growth. In their conceptual writings on how an Africentric worldview benefits psychological functioning, Fine, Schwebel, and Myers (1985) and others (e.g., Akbar, 1979; 
Myers et al., 1996) have suggested that an Africentric worldview provides a positive framework from which challenges are viewed as "positive and useful events" (Myers et al., 1996, p. 22) and as opportunities for growth (Jackson \& Sears, 1992). Thus, an event that might typically be thought of as stressful, such as failing an exam, might instead be viewed as positive or having the capacity to enhance well-being. Although we did not assess whether stressful situations were appraised as harmful, threatening, or challenging, the finding that perceived stress mediated the relationship between Africentric worldview and depressive symptoms is consistent with the notion that Africentric worldview influences appraisals of stress.

A second possible explanation for the observed buffering effect of Africentric worldview has to do with performance expectations. Individuals with unrealistically high performance expectations are more likely to be disappointed, rate themselves negatively, and experience negative feelings when met with failure than are individuals with more reasonable, relaxed performance expectations (Lazarus \& Folkman, 1984). It may be that the differential impact of stress on depressive symptoms for individuals with high and low Africentric beliefs is a function of the influence of an Africentric worldview on performance expectations. Myers and colleagues (1996) suggested that the spiritual/nonmaterial essence of an Africentric worldview is reflected by less emphasis on material criteria such as appearance, academic degrees, and possessions and more emphasis on intrinsic self-worth. This decreased emphasis counteracts the unstable and transient nature of material, external criteria, which are likely to result in feelings of insecurity, anxiety, and depression (Myers et al., 1996). Furthermore, an Africentric worldview emphasizes the "survival of the corporate whole ... rather than simply advancing some special interest group or some segment apart from the corporate whole" (Kambon, 2004, p. 84). Thus, it may be that, for those with an Africentric worldview, the emphasis on spirituality and survival of the group translates into qualitatively different expectations concerning performance when compared with the perspective of individuals who emphasize competition (e.g., survival of the fittest) and materialism (i.e., a low Africentric worldview).

Attributions for negative events are yet a third mechanism by which having an Africentric worldview may protect against stress. Lazarus and Folkman (1984) held that internal attributions for failure may lead to more negative effects of stress than do external ones. Individuals who endorse an Africentric worldview and have greater intrinsic self-worth as a result (Myers et al., 1996) may possess more positive self-esteem and self-confidence and a more positive self-concept as a whole and be less likely to blame themselves for failure and/ or other stressful occurrences. Indeed, self-concept has been described as a mediating resource for the effects of stress (Lazarus \& Folkman, 1984). Alternatively, the Africentric emphasis on cooperation and group orientation may have the potential to reduce excessive forms of stress as the burden of responsibility for failure following stress is shared and not due to just one person's efforts (Myers et al., 1996). Taken together, these "other source" attributions might decrease the likelihood of negative self-attributions regarding failure and, over time, increase the likelihood of positive psychological adjustment.

A fourth set of mechanisms focuses on coping. First, Lazarus and Folkman (1984) suggested that individuals' ability to accurately evaluate or appraise available coping resources can decrease the negative influence of stress on their adjustment. Those who are passed over for a promotion and appraise "doing nothing about it" as their only viable coping strategy are more likely to be negatively impacted by the stressful event than are those who explore either accepting the situation or accepting another job as viable alternatives (Lazarus \& Folkman, 1984). In the same way that an Africentric worldview conveys a positive framework with regard to the appraisal of stress as challenging instead of as harmful or threatening, such a framework may also allow individuals to be more optimistic about the range of available coping resources for dealing with a stressful situation. 
A second coping mechanism concerns coping effectiveness, or the use of coping strategies that mitigate stress by managing the stress itself as well as the negative feelings associated with the stress (Lazarus \& Folkman, 1984). We expected that Africentric worldview would be mediated by emotion- and problem-focused coping, but we found a partial mediation effect only for emotion-oriented coping. Thus, individuals who endorsed an Africentric worldview were less likely to resort to strategies such as denying, ignoring, and suppressing. These strategies are thought to exacerbate stress and are commonly associated with negative affect such as depression (e.g., see Clark, 2004; Neville et al., 1997; Wegner, Schneider, Carter, \& White, 1987).

The absence of a relationship between Africentric worldview and problem-focused coping strategies in the present sample suggests that an Africentric perspective does not correspond to problem-focused coping strategies as operationalized in the current study. Interestingly, Myers et al. (1996) suggested that individuals endorsing an Africentric worldview actively engage conflicts or challenges by evaluating and arresting self-defeating and other negative thoughts. Thus, the active engagement in challenges and conflicts might translate into decreased emotion-focused coping strategies (as we found in the present study) and not specific problem-focused strategies. It is also possible that an Africentric worldview is associated with other kinds of active strategies that were not adequately captured by the coping instrument used in the present investigation. For example, Africentric worldview has been theoretically linked to mindfulness and openness to new information as well as reliance on strategies such as empathy, trust, humor, forgiveness, assertiveness, and honesty (Myers et al., 1996). We might also expect that an Africentric worldview, due to its emphasis on interconnectedness and cooperative effort, would be associated with strategies such as social support seeking. Future studies of Africentric worldview should explore its relationships to social support seeking as well as other Africultural coping strategies (Utsey, Adams, \& Bolden, 2000) that may not be captured by the traditional emotion- and problem-focused coping framework.

\section{Study Implications}

The present findings highlight the continued need for studies to integrate the theoretical concepts of stress with those of ethnicity and culture (Jackson \& Sears, 1992; Smith, 1985). Although recent work examining racial identity as a protective factor against the impact of race-related stress on indices of mental health has produced a strong effort in this direction (e.g., Sellers \& Shelton, 2003), the current study calls attention to Africentric worldview as a cultural protective factor with implications for perceived stress in African American populations. Furthermore, the present findings open the door for enhancing delivery services provided to African American clients. For example, counselors who are familiar with an Africentric worldview may be in a stronger position to exhibit greater sensitivity to their clients' behaviors, perceptions, thinking, and feelings and thereby could better understand their clients and facilitate their clients' progress. As counselors and clinicians become more aware of the perspective and cultural orientation of their African American clients, greater familiarity with an Africentric worldview could play a role in decreasing the all-too-familiar outcome of premature termination of services seen in many African American clients who seek services (Cokley \& Williams, 2005) only to find that the services they are receiving are inconsistent with their own cultural values. Furthermore, the protective nature of an Africentric worldview against stress carries implications for the development of culturally sensitive treatment interventions that incorporate Africentric values and an Africentric worldview. A handful of such therapies and treatment interventions have been articulated in the past (Duncan, 2006; Myers, 1988; Phillips, 1990) and hold promise for treating affective disorders and improving overall psychological health (e.g., Townsend, Hawkins, \& Batts, 2007). 


\section{Limitations and Future Directions}

Although the current study makes several worthwhile contributions to the extant literature, several limitations of the present study will need to be addressed in future research. First, future examinations of the role of an Africentric worldview will need to extend beyond PWI samples to include larger representative samples, because other African Americans may think about and experience stress differently. Second, future studies should move beyond generic measures of stress to also examine race-related stress. The ability of an Africentric worldview to buffer stress related to being African American will go a long way toward increasing confidence in the conceptual foundation and framework of an Africentric worldview. Third, we were unable to tell whether perceived stress led to depressive symptoms or, in the case of our mediational analyses, depressive symptoms led to increases in perceived stress and emotion-focused coping strategies. Future studies will need to investigate the relationships among study constructs over time in order to develop a clearer picture of how an Africentric worldview acts to influence psychological adjustment. Finally, the present study assessed general coping in the past 6 months without specific reference to what respondents were coping with. Our ability to draw conclusions about underlying mechanisms such as an Africentric worldview's influence on stress and coping appraisal, performance expectations, attributions, and so on will require methodological approaches that examine an Africentric worldview in the context of specific situations or instances of stress.

\section{Conclusion}

In the present study, we examined the protective nature of an Africentric worldview with regard to the association between perceived stress and depressive symptoms, as well as the mediating influence of perceived stress and coping in the relationship between an Africentric worldview and coping. These data are among the first to offer empirical support for the protective nature of an Africentric worldview and highlight the need for more studies that explore an Africentric worldview as a viable resilience factor in African Americans' psychological and mental health outcomes. Given the relative dearth of studies examining Africentric worldview as an important psychological factor for African Americans, we issue a call for more studies investigating this important culturally relevant construct. Such studies will increase the breadth of cultural perspectives brought to the table with regard to enhancing African Americans' mental health and will promote cultural sensitivity awareness as well as African Americans' mental health and wellness.

\section{Acknowledgments}

We thank Nicole Gardner Neblett for her thoughtful comments on earlier versions of this article.

\section{References}

Akbar, N. African roots of Black personality. In: Smith, WD.; Burlew, AK., editors. Reflections on Black psychology. University of America Press; Washington, DC: 1979. p. 64-86.

Akbar, N. Mental disorder among African Americans. In: Jones, R., editor. Black psychology. 3rd ed.. Cobb \& Henry; Berkeley, CA: 1991. p. 339-352.

Asante, MK. Afrocentricity: The theory of social change. African American Images; Chicago, IL: 2003.

Azibo D. Some psychological concomitants and consequences of the Black personality: Mental health implications. Journal of Non-White Concerns in Personnel and Guidance 1983;11:59-66.

Azibo, DA. Mental health defined Africentrically. In: Azibo, DA., editor. African psychology in historical perspective and related commentary. Africa World Press; Trenton, NJ: 1996. p. 47-56.

Baldwin J. Notes on an Afrocentric theory of Black personality. Western Journal of Black Studies 1981;5:172-179. 
Baldwin J, Bell Y. The African Self-Consciousness Scale: An Africentric personality questionnaire. Western Journal of Black Studies 1985;9:61-68.

Baron RM, Kenny DA. The moderator-mediator variable distinction in social psychological research: Conceptual, strategic, and statistical considerations. Journal of Personality and Social Psychology 1986;51:1173-1182. [PubMed: 3806354]

Beck AT, Ward CH, Mendelson M, Mock J, Erbaugh J. An inventory for measuring depression. Archives of General Psychiatry 1961;4:53-63.

Belgrave, FZ.; Allison, KW. African American psychology: From Africa to America. Sage; Thousand Oaks, CA: 2006.

Belgrave FZ, Townsend TG, Cherry VR, Cunningham DM. The influence of an Africentric worldview and demographic variables on drug knowledge, attitudes, and use among African American youth. Journal of Community Psychology 1997;25:421-433.

Brookins CC. The relationship between Afrocentric values and racial identity attitudes: Validation of the Belief Systems Analysis Scale on African American college students. Journal of Black Psychology 1994;20:128-142.

Butler, J. Of kindred minds: The ties that bind. In: Orlandi, MA.; Weston, R.; Epstein, LG., editors. Cultural competence for evaluators: A guide for alcohol and other drug abuse prevention practitioners working with ethnic/racial communities. U.S. Department of Health and Human Services, Office for Substance Abuse Prevention; Rockville, MD: 1992. p. 23-54.

Chapman LK, Kertz SJ, Woodruff-Borden J. A structural equation model analysis of perceived control and psychological distress on worry among African American and European American young adults. Journal of Anxiety Disorders 2009;23:69-76. [PubMed: 18487036]

Clark R. Interethnic group and intraethnic group racism: Perceptions and coping in Black university students. Journal of Black Psychology 2004;30:506-526.

Cohen, J.; Cohen, P. Applied multiple regression/correlation analysis for the behavioral sciences. 2nd ed.. Erlbaum; Hillsdale, NJ: 1983.

Cokley K, Williams W. A psychometric examination of the Africentric Scale: Challenges in measuring Africentric values. Journal of Black Studies 2005;35:827-843.

DeLongis A, Coyne JC, Dakof G, Folkman S, Lazarus RS. Relationship of daily hassles, uplifts, and major life events to health status. Health Psychology 1982;1:119-136.

Derogatis, LR. SCL-90-R: Administration, scoring, and procedures manual II for the revised version. Clinical Psychometric Research; Towson, MD: 1983.

Duncan, LE.; Helmeke, KB.; Sori, CF. The therapist's notebook for integrating spirituality in counseling: Homework, handouts and activities for use in psychotherapy. Haworth Press; New York, NY: 2006. Using concepts of NTU psychotherapy to encourage the use of prayer: Overcoming distress and trauma in Christian clients; p. 251-255.

Edmunds GJ. Needs assessment strategy for Black students: An examination of stressors and program implications. Journal of Non-White Concerns in Personnel and Guidance 1984;12:48-56.

Fine MA, Schwebel AI, Myers LJ. The effects of world-view on adaptation to single parenthood among middle-class adult women. Journal of Family Issues 1985;6:107-172.

Frank, JD. Persuasion and healing. Schocken Books; New York, NY: 1977.

Frydenberg, E. Adolescent coping: Theoretical and research perspectives. Routledge; New York, NY: 1997.

Grills, CT. African psychology. In: Jones, RL., editor. Black psychology. 4th ed.. Cobb \& Henry; Hampton, VA: 2004. p. 171-208.

Gulick EE. Coping among spouses or significant others of persons with multiple sclerosis. Nursing Research 1995;44:220-225. [PubMed: 7624232]

Hamilton M. A rating scale for depression. Journal of Neurology, Neurosurgery \& Psychiatry 1960;23:56-61.

Harrell SP. A multidimensional conceptualization of racism-related stress: Implications for the well-being of people of color. American Journal of Orthopsychiatry 2000;70:42-57. [PubMed: 10702849]

Hatter DY, Ottens AJ. Africentric world view and Black students' adjustment to a predominantly White university: Does worldview matter? College Student Journal 1998;32:472-480. 
Helms, JE.; Parham, TA. Black Racial Identity Attitudes Scale (Form RIAS-B). In: Helms, JE., editor. Black and White racial identity. Greenwood Press; New York, NY: 1990. p. 245-247.

Holmbeck GN. Toward terminological, conceptual, and statistical clarity in the study of mediators and moderators: Examples from the child-clinical and pediatric psychology literatures. Journal of Consulting and Clinical Psychology 1997;65:599-610. [PubMed: 9256561]

Israelski DM, Prentiss DE, Jubega S, Balmas G, Garcia P, Muhammad M, Koopman C. Psychiatric comorbidity in vulnerable populations receiving primary care for HIV/AIDS. AIDS Care 2007;19:220 225. [PubMed: 17364402]

Jackson AP, Sears SJ. Implications of an Africentric worldview in reducing stress for African American women. Journal of Counseling \& Development 1992;71:184-190.

Jalowiec A, Murphy SP, Powers MJ. Psychometric assessment of the Jalowiec Coping Scale. Nursing Research 1984;33:157-161. [PubMed: 6563533]

Jalowiec A, Powers MJ. Stress and coping in hypertensive and emergency room patients. Nursing Research 1981;30:10-15. [PubMed: 6906008]

Joe S, Woolley ME, Brown GK, Ghahramanlou-Holloway M, Beck AT. Psychometric properties of the Beck Depression Inventory-II in low-income, African American suicide attempters. Journal of Personality Assessment 2008;90:521-523. [PubMed: 18704812]

Kambon, KK. The African personality in America: An African-centered framework. Nubian Nation; Tallahassee, FL: 1992.

Kambon, K. Nubian Nation; Tallahassee, FL: 2003. Cultural misorientation.

Kambon, K. The worldviews paradigm as the conceptual frame-work for African/Black psychology. In: Jones, R., editor. Black psychology. 4th ed.. Cobb \& Henry; Hampton, VA: 2004. p. 73-92.

Kashani JH, Priesmeyer M. Differences in depressive symptoms and depression among college students. American Journal of Psychiatry 1983;140:1081-1082. [PubMed: 6869598]

Lazarus, R.; Folkman, S. Stress, appraisal and coping. Springer; New York, NY: 1984.

MacKinnon DP, Dwyer JH. Estimating mediated effects in prevention studies. Evaluation Review 1993;17:144-158.

Mbiti, J. African religions and philosophies. Anchor Books/Doubleday; Garden City, NY: 1970.

Millet, P. Unpublished doctoral dissertation. Ohio State University; Columbus: 1993. Predicting depression, stress, and self-esteem in Black and White students at a predominantly White university.

Montgomery DE, Fine MA, James-Myers L. The development and validation of an instrument to assess an optimal Afrocentric world view. Journal of Black Psychology 1990;17:37-54.

Myers, LJ. Understanding an Afrocentric world-view: Introduction to an optimal psychology. KendallHunt; Dubuque, IA: 1988.

Myers, LJ.; Montgomery, D.; Fine, M.; Reese, R. Belief System Analysis Scale and Belief and Behavior Awareness Scale Development: Measuring an optimal, Afrocentric world-view. In: Jones, RL., editor. Handbook of tests and measurements for Black populations. Vol. 2. Cobb \& Henry; Hampton, VA: 1996. p. 19-35.

Neville HA, Heppner PP, Wang L. Relations among racial identity attitudes, perceived stressors, and coping styles in African American college students. Journal of Counseling \& Development 1997;75:303-311.

Nobles WW. Africanity: Its role in Black families. Black Scholar 1974;5:10-17.

Nobles, W. African philosophy: Foundations for Black psychology. In: Jones, R., editor. Black psychology. 2nd ed.. Harper \& Row; New York, NY: 1980. p. 23-36.

Nobles, WW. African philosophy: Foundations of black psychology. In: Jones, R., editor. Black psychology. Cobb \& Henry; Berkeley, CA: 1991. p. 47-63.

Phillips FB. NTU psychotherapy: An Afrocentric approach. Journal of Black Psychology 1990;17:5574.

Picot SJ. Rewards, costs, and coping of African American caregivers. Nursing Research 1995;44:147152. [PubMed: 7761290]

Plummer DL, Slane S. Patterns of coping in racially stressful situations. Journal of Black Psychology 1996;22:302-315. 
Preacher, KJ.; Leonardelli, GJ. Calculation for the Sobel test: An interactive calculation tool for mediation tests. 2001. Retrieved May 20, 2009, from http://www.people.ku.edu/ preacher/sobel/sobel.htm

Samuel-Hodge CD, Watkins DC, Rowell KL, Hooten EG. Coping styles, well-being, and self-care behaviors among African Americans with Type 2 diabetes. Diabetes Educator 2008;34:501-510. [PubMed: 18535323]

Sasaki M, Yamasaki K. Stress, coping, and the adjustment process among university freshmen. Counselling Psychology Quarterly 2007;20:51-67.

Sellers RM, Shelton JN. The role of racial identity in perceived racial discrimination. Journal of Personality and Social Psychology 2003;84:1079-1092. [PubMed: 12757150]

Shaver, PR.; Brennan, KA. Measures of depression and loneliness. In: Robinson, JP.; Shaver, PR.; Wrightsman, LS., editors. Measures of Social Psychological Attitudes: Vol. 1. Measures of personality and social psychological attitudes. Academic Press; San Diego, CA: 1991. p. 195-289.

Smith E. Ethnic minorities: Life stress, social support, and mental health issues. Counseling Psychologist 1985;3:537-575.

Stein JA, Nyamathi A. Gender differences in relationships among stress, coping, and health risk behaviors in impoverished, minority populations. Personality and Individual Differences 1999;26:141-157.

Townsend TG, Hawkins SR, Batts AL. Stress and stress reduction among African American women: A brief report. Journal of Primary Prevention 2007;28:569-582. [PubMed: 18273708]

Utsey SO, Adams EP, Bolden M. Development and initial validation of the Africultural Coping Systems Inventory. Journal of Black Psychology 2000;26:194-215.

Wegner DM, Schneider DJ, Carter SR, White TL. Paradoxical effects of thought suppression. Journal of Personality and Social Psychology 1987;53:5-13. [PubMed: 3612492]

Worrell FC, Vandiver BJ, Cross WE Jr. The Cross Racial Identity Scale: Technical manual. 2000 Unpublished manual. 


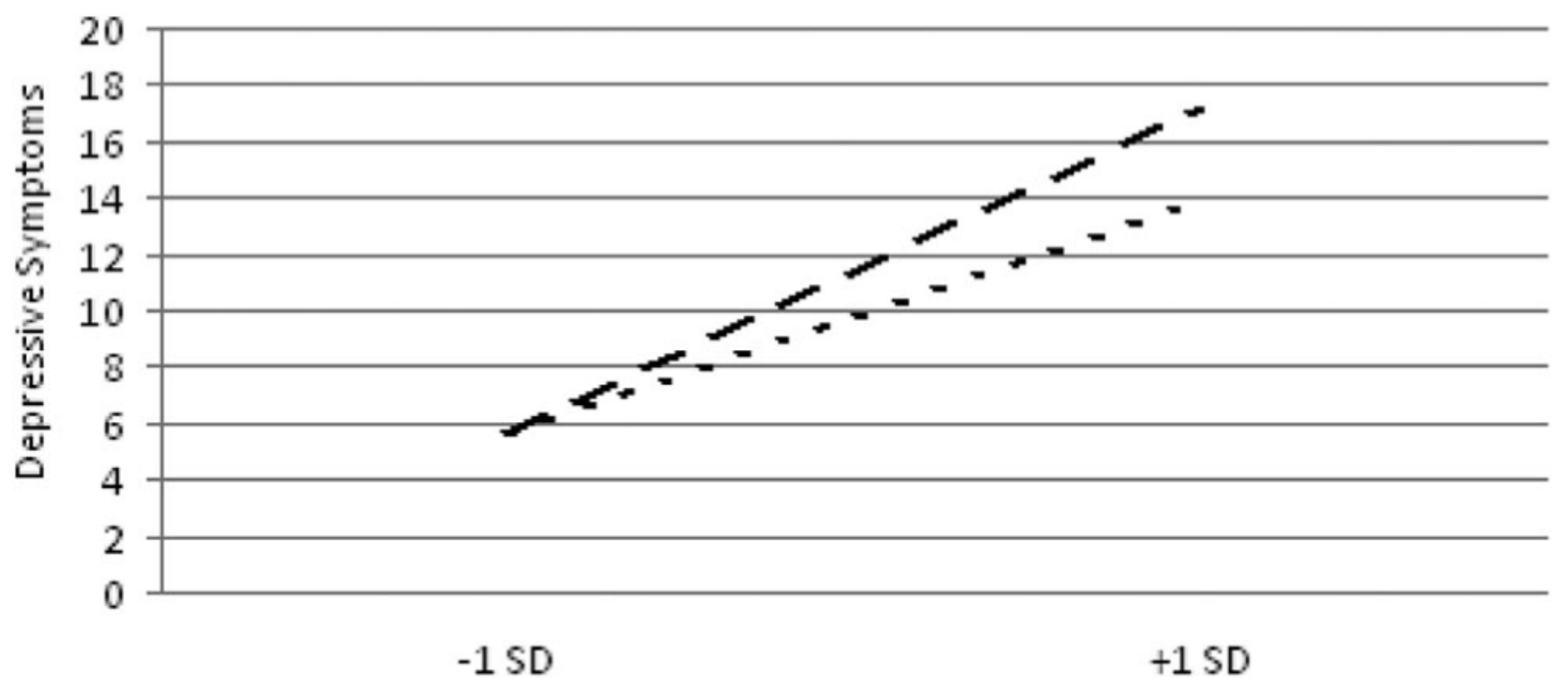

\section{Perceived Stress}

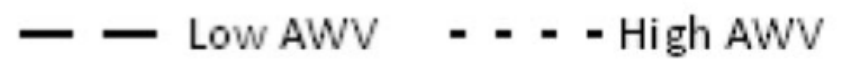

Figure 1.

The interaction of perceived stress and Africentric worldview (AWV) on depressive symptoms. 


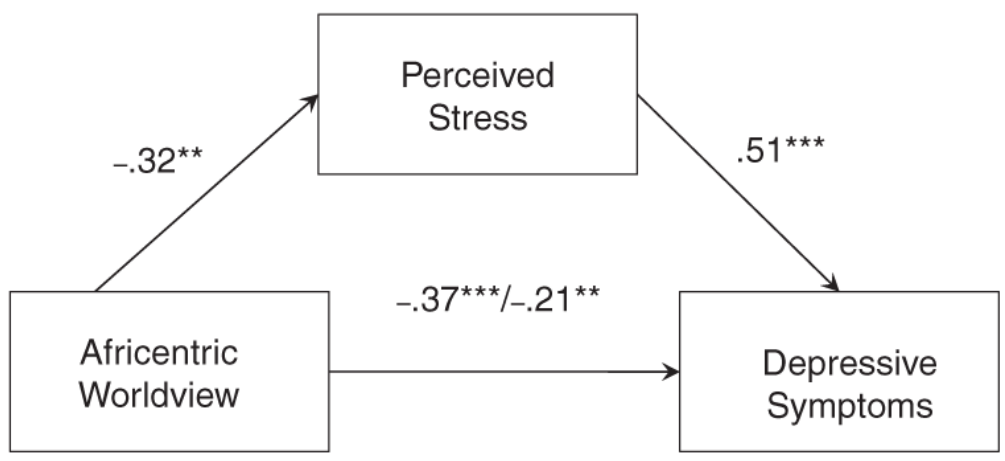

Figure 2.

Mediation model for Africentric worldview, perceived stress, and depressive symptoms. ** $p<.01 . * * * p<.001$. 


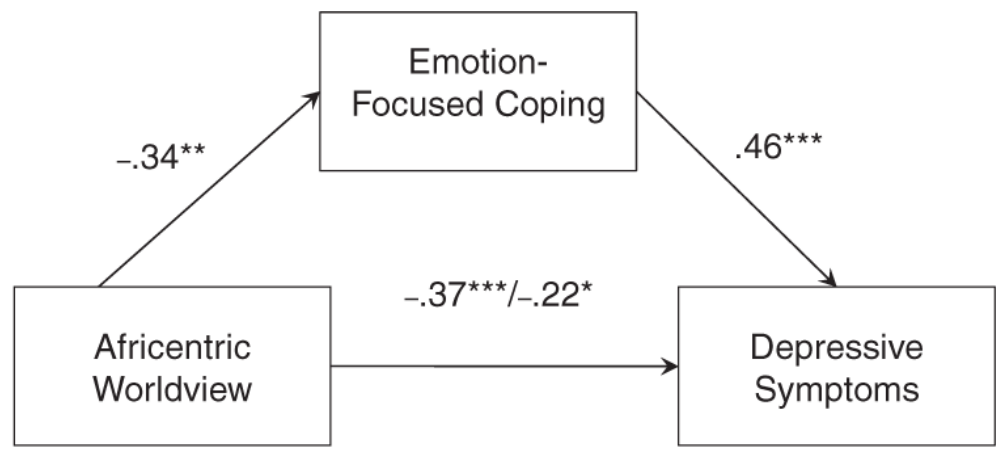

Figure 3.

Mediation model for Africentric worldview, emotion-focused coping, and depressive symptoms. $* p<.05$. ** $p<.01$. *** $p<.001$. 


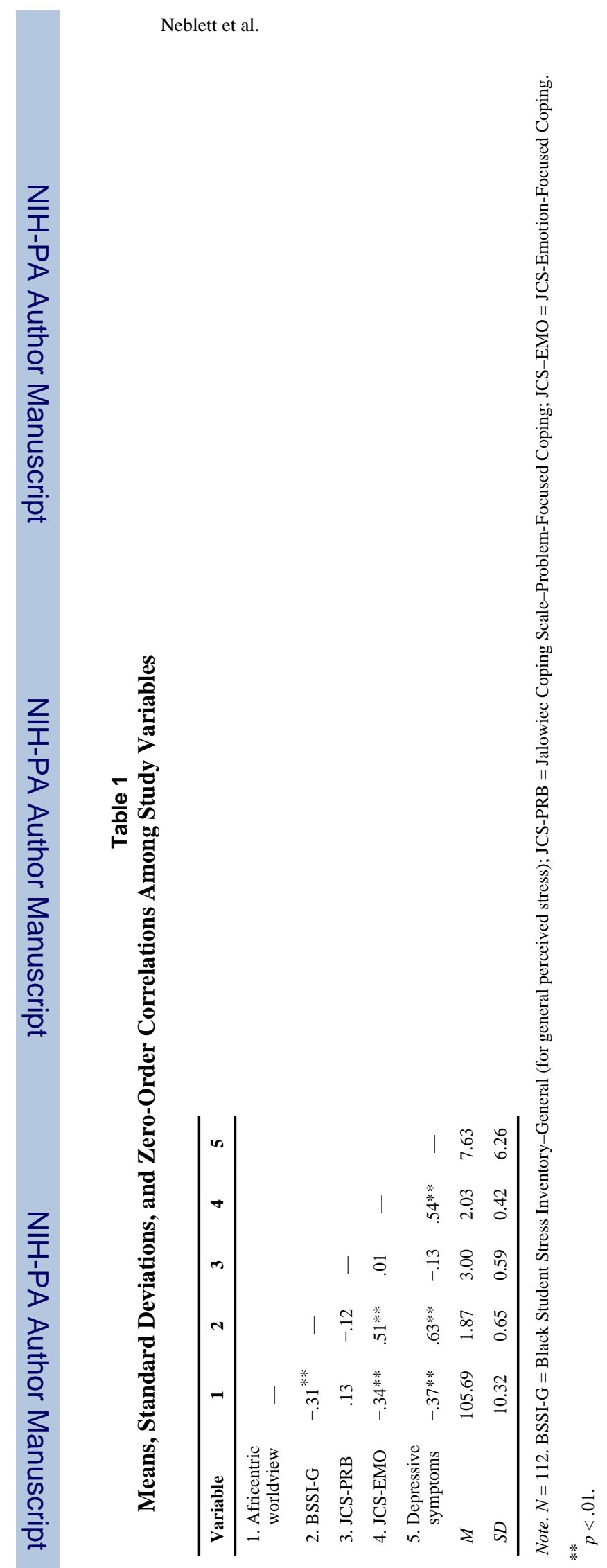

J Couns Psychol. Author manuscript; available in PMC 2010 May 4. 


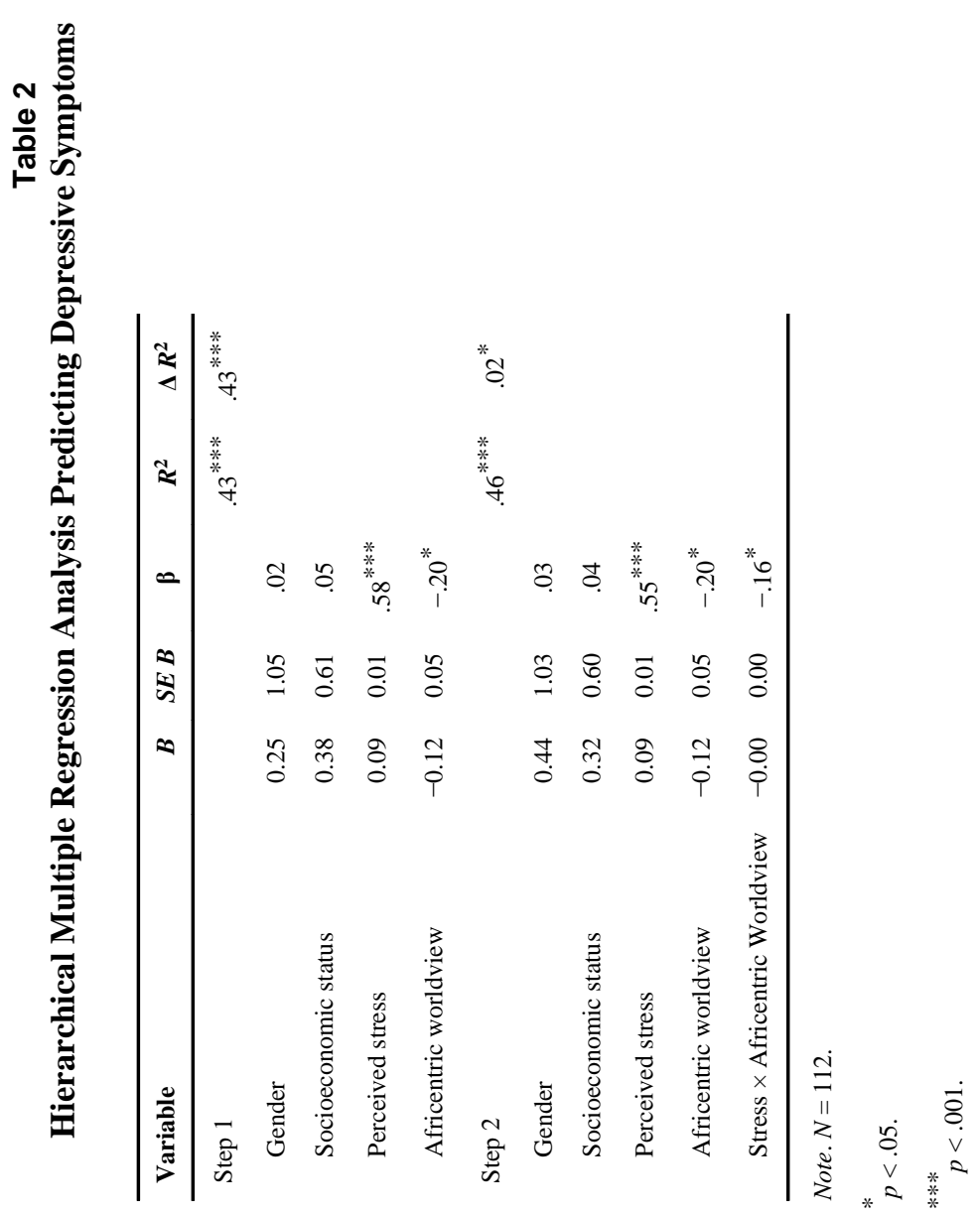

